\title{
The association between insulin use and volumetric bone mineral density, bone micro-architecture and bone strength of the distal radius in patients with type 2 diabetes - The Maastricht study
}

Citation for published version (APA):

de Waard, E. A. C., Driessen, J. H. M., de Jong, J. J. A., van Geel, T. A. C. M., Henry, R. M. A., van Onzenoort, H. A. W., Schram, M. T., Dagnelie, P. C., van der Kallen, C. J., Sep, S. J. S., Stehouwer, C. D. A., Schaper, N. C., Koster, A., Savelberg, H. H. C. M., Neef, C., Geusens, P. P. M. M., de Vries, F., \& van den Bergh, J. P. W. (2017). The association between insulin use and volumetric bone mineral density, bone micro-architecture and bone strength of the distal radius in patients with type 2 diabetes - The Maastricht study. Bone, 101, 156-161. https://doi.org/10.1016/j.bone.2017.05.004

Document status and date:

Published: 01/08/2017

DOI:

10.1016/j.bone.2017.05.004

Document Version:

Publisher's PDF, also known as Version of record

Document license:

Taverne

Please check the document version of this publication:

- A submitted manuscript is the version of the article upon submission and before peer-review. There can be important differences between the submitted version and the official published version of record. People interested in the research are advised to contact the author for the final version of the publication, or visit the DOI to the publisher's website.

- The final author version and the galley proof are versions of the publication after peer review.

- The final published version features the final layout of the paper including the volume, issue and page numbers.

Link to publication

\footnotetext{
General rights rights.

- You may freely distribute the URL identifying the publication in the public portal. please follow below link for the End User Agreement:

www.umlib.nl/taverne-license

Take down policy

If you believe that this document breaches copyright please contact us at:

repository@maastrichtuniversity.nl

providing details and we will investigate your claim.
}

Copyright and moral rights for the publications made accessible in the public portal are retained by the authors and/or other copyright owners and it is a condition of accessing publications that users recognise and abide by the legal requirements associated with these

- Users may download and print one copy of any publication from the public portal for the purpose of private study or research.

- You may not further distribute the material or use it for any profit-making activity or commercial gain

If the publication is distributed under the terms of Article 25fa of the Dutch Copyright Act, indicated by the "Taverne" license above,

Download date: 26 Apr. 2023 
Full Length Article

\title{
The association between insulin use and volumetric bone mineral density, bone micro-architecture and bone strength of the distal radius in patients with type 2 diabetes - The Maastricht study
}

\author{
E.A.C. de Waard ${ }^{\text {a,b,*,1 }}$, J.H.M. Driessen ${ }^{\text {b,c,d,e, }, 1}$, J.J.A. de Jong ${ }^{\text {a,b }}$, T.A.C.M. van Geel ${ }^{\text {d,f }}$, R.M.A. Henry ${ }^{\text {g,h,i }}$, \\ H.A.W. van Onzenoort ${ }^{\text {e,j }}$, M.T. Schram ${ }^{\text {g,h,i }}$, P.C. Dagnelie ${ }^{\text {d,h,k }}$, C.J. van der Kallen ${ }^{\text {g,h }}$, S.J.S. Sep ${ }^{\text {g,h }}$, \\ C.D.A. Stehouwer $^{\text {g,h }}$, N.C. Schaper ${ }^{\text {d,g,h }}$, A. Koster ${ }^{\text {d,l }}$, H.H.C.M. Savelberg b,m ${ }^{\text {, C. Neef }}{ }^{\text {d,e }}$, P.P.M.M. Geusens ${ }^{\text {d,g,n }}$, \\ F. de Vries ${ }^{\mathrm{c}, \mathrm{d}, \mathrm{e}, \mathrm{o}}$, J.P.W. van den Bergh ${ }^{\mathrm{b}, \mathrm{g}, \mathrm{p}}$
}

a Maastricht University, Department of Internal Medicine, Maastricht, The Netherlands

${ }^{\mathrm{b}}$ NUTRIM School for Nutrition and Translational Research in Metabolism, Maastricht University, Maastricht, The Netherlands

c Utrecht Institute of Pharmaceutical Sciences, Division of Pharmacoepidemiology and Clinical Pharmacology, Utrecht, The Netherlands

d CAPHRI School for Public Health and Primary Care, Maastricht University, Maastricht, The Netherlands

e Maastricht University Medical Center +, Department of Clinical Pharmacy and Toxicology, Maastricht, The Netherlands

${ }^{\mathrm{f}}$ Maastricht University, Department of Family Medicine, Maastricht, The Netherlands

g Maastricht University Medical Center +, Department of Internal Medicine, Maastricht, The Netherlands

h CARIM School for Cardiovascular Diseases, Maastricht University, Maastricht, The Netherlands

${ }^{\mathrm{i}}$ Maastricht University Medical Center +, Heart and Vascular Center, Maastricht, The Netherlands

${ }^{\mathrm{j}}$ Radboud University Nijmegen Medical Center, Department of Pharmacy, Nijmegen, The Netherlands

${ }^{\mathrm{k}}$ Maastricht University, Department of Epidemiology, Maastricht, The Netherlands

${ }^{1}$ Maastricht University, Department of Social Medicine, Maastricht, The Netherlands

m Maastricht University, Department of Human Movement Science, Maastricht, The Netherlands

${ }^{\mathrm{n}}$ University of Hasselt, Biomedical Research Institute, Hasselt, Belgium

${ }^{\circ}$ MRC Epidemiology Lifecourse Unit, Southampton General Hospital, Southampton, United Kingdom

${ }^{\mathrm{p}}$ VieCuri Medical Center, Department of Internal Medicine, Subdivision of Endocrinology, Venlo, The Netherlands

\section{A R T I C L E I N F O}

\section{Article history:}

Received 16 January 2017

Revised 24 April 2017

Accepted 2 May 2017

Available online 6 May 2017

\section{Keywords:}

Insulin use

Type 2 diabetes mellitus

High-resolution peripheral quantitative com-

puted tomography (HR-pQCT)

Volumetric bone mineral density

Bone micro-architecture

Bone strength

\begin{abstract}
A B S T R A C T
Type 2 diabetes mellitus (T2DM) has been associated with an increased risk of fractures, despite normal to increased bone mineral density (BMD). Insulin use is one of the factors linked to this increased fracture risk. However, direct negative effects of insulin on bone quality are not expected since insulin is thought to be anabolic to bone. In this cross-sectional study the association between insulin use and volumetric BMD (vBMD), bone microarchitecture and bone strength of the distal radius, as measured with HR-pQCT, was examined. Data from 50 participants with T2DM of The Maastricht Study (mean age $62 \pm 7.5$ years, $44 \%$ women) was used. Participants were classified as insulin user $(n=13)$ or non-insulin user $(n=37)$ based on prescription data. Linear regression analysis was used to estimate the association between current insulin use and HR-pQCT derived parameters. After adjustment for age, sex, body mass index, glycated hemoglobin A1c and T2DM duration, insulin use was associated with lower total vBMD (standardized beta $(\beta):-0.56(95 \% \mathrm{CI}:-0.89$ to -0.24$)$ ), trabecular vBMD $(\beta$ : -0.58 ( $95 \% \mathrm{CI}:-0.87$ to -0.30$)$ ), trabecular thickness ( $\beta:-0.55$ ( $95 \% \mathrm{CI}:-0.87$ to -0.23$)$ ), cortical thickness $(\beta:-0.41(95 \% \mathrm{CI}:-0.74$ to -0.08$))$, log cortical pore volume $(\beta:-0.43(95 \% \mathrm{CI}:-0.73$ to -0.13$))$, bone stiffness ( $\beta$ : -0.39 (95\% CI: -0.62 to -0.17$))$ and failure load $(\beta:-0.39(95 \% \mathrm{Cl}:-0.60$ to -0.17$))$ when compared to the non-insulin users. Insulin use was not associated with cortical vBMD, trabecular number, trabecular separation, cortical porosity and cortical pore diameter. This study indicates that insulin use is negatively associated
\end{abstract}

Abbreviations: aBMD, areal bone mineral density; AGE, advanced glycation end product; ATC, anatomical therapeutical chemical; $\beta$, standardized beta; BMD, bone mineral density; $C \mathrm{I}$

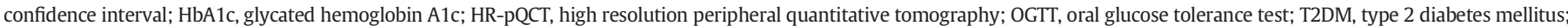
vBMD, volumetric bone mineral density.

* Corresponding author at: Universiteitssingel 40, room C5.535, P.0. Box 5800, 6202, AZ, Maastricht, The Netherlands.

E-mail addresses: e.dewaard@maastrichtuniversity.nl (E.A.C. de Waard), annemariek.driessen@mumc.nl (J.H.M. Driessen), joost.dejong@maastrichtuniversity.nl (J.J.A. de Jong), tineke.vangeel@maastrichtuniversity.nl (T.A.C.M. van Geel), rma.henry@mumc.nl (R.M.A. Henry), Hein.vanOnzenoort@radboudumc.nl (H.A.W.van Onzenoort), m.schram@mumc.nl (M.T. Schram), dagnelie@maastrichtuniversity.nl (P.C. Dagnelie), c.vanderkallen@maastrichtuniversity.nl (C.J. van der Kallen), s.sep@mumc.nl (S.J.S. Sep), cda.stehouwer@mumc.nl (C.D.A. Stehouwer), n.schaper@mumc.nl (N.C. Schaper), a.koster@maastrichtuniversity.nl (A. Koster), hans.savelberg@maastrichtuniversity.nl (H.H.C.M. Savelberg), c.neef@maastrichtuniversity.nl (C. Neef), piet.geusens@scarlet.be (P.P.M.M. Geusens), frank.de.vries@mumc.nl (F. de Vries), jvdbergh@viecuri.nl (J.P.W. van den Bergh).

${ }^{1}$ E.A.C. de Waard and J.H.M. Driessen contributed equally. 
with bone density, bone micro-architectural and bone strength parameters. These findings may partly explain the previously observed increased fracture risk in insulin users, although there may be residual confounding by other factors related to disease severity in insulin users.

(c) 2017 Elsevier Inc. All rights reserved.

\section{Introduction}

Type 2 diabetes mellitus (T2DM) is a highly prevalent chronic disease leading to complications such as neuropathy, retinopathy and nephropathy [1]. More recently, T2DM has been associated with an increased risk of fractures, despite a normal to increased bone mineral density (BMD) $[2,3]$. The mechanisms leading to this increased fracture risk are not completely elucidated, but both an increased falling frequency and bone fragility are thought to contribute to the increased fracture risk $[4,5]$. Bone fragility can be the result of various factors, and in patients with T2DM, among others, unfavorable changes in micro- and macro-architecture of the bone, accumulation of advanced glycation end products (AGEs) in bone collagen and a low bone turnover have been reported $[4,5]$.

The use of antihyperglycemic drugs may also contribute to the increased fracture risk. Except for thiazolidinediones, oral antihyperglycemic drugs are not associated with an increased fracture risk [6,7] However, insulin has been associated with an increased fracture risk [7]. Since previous studies showed that insulin may be anabolic to bone [8] it has been hypothesized that the increased fracture risk in insulin users is not caused by the drug itself. It is rather due to an increased falling frequency and to the long-term negative effects of hyperglycemia on bone quality, as insulin is most often used in patients with long disease duration.

The association between hyperinsulinemia and areal BMD (aBMD) in nondiabetic participants, as measured with DXA, has been examined in several studies that demonstrated a positive association between hyperinsulinemia and aBMD [9-11]. However, only two small studies have examined the association between insulin therapy and aBMD in patients with T2DM. Both showed a positive correlation between insulin dose and aBMD [12,13].

High resolution peripheral quantitative computed tomography (HR$\mathrm{pQCT}$ ) is a relatively new technique which can be used to measure volumetric BMD (vBMD), micro-architecture and bone strength $[14,15]$. The association between insulin use and bone parameters measured by HR-pQCT has not been studied before [7]. Therefore, the aim of this study was to examine the association between insulin use and vBMD, bone micro-architecture and bone strength in participants with T2DM. It is hypothesized that insulin use will be positively associated with HR-pQCT derived parameters when compared to non-insulin use.

\section{Materials and methods}

\subsection{Source population}

Data from The Maastricht Study, an ongoing observational prospective population-based cohort study, was used in the present study. The rationale and methodology have been described previously [16]. In brief, the study focuses on the etiology, pathophysiology, complications and comorbidities of T2DM and is characterized by an extensive phenotyping approach. Eligible participants were all individuals aged between 40 and 75 years and living in the southern part of the Netherlands. Participants were recruited through mass media campaigns as well as from the municipal registries and the regional Diabetes Patient Registry via mailings. Recruitment was stratified according to known T2DM status, with an oversampling of individuals with T2DM, for reasons of efficiency.

To determine glucose metabolism status, all participants, except those who used insulin, underwent a standardized 2-h $75 \mathrm{~g}$ oral glucose tolerance test (OGTT) after an overnight fast. For safety reasons, participants with a fasting glucose level $>11.0 \mathrm{mmol} / \mathrm{l}(>200.0 \mathrm{mg} / \mathrm{dl})$, as determined by a capillary blood glucose measurement, did not undergo the OGTT. Fasting glucose level, 2-h plasma glucose level and information about diabetes medication were used to determine glucose metabolism status. Participants were classified as having T2DM when they had a fasting plasma glucose level $\geq 7.0 \mathrm{mmol} / \mathrm{l}(\geq 126 \mathrm{mg} / \mathrm{dl})$ or a two hour plasma glucose level $\geq 11.1 \mathrm{mmol} / \mathrm{l}$ ( $\geq 200 \mathrm{mg} / \mathrm{dl}$ ) as specified by the World Health Organization guidelines [17] or if they used antihyperglycemic drugs at baseline. Individuals without type 1 diabetes who used antihyperglycemic drugs were classified as having T2DM. Participants who were not classified as T2DM, but did use an antihyperglycemic drug in the six months prior to the date of the HRpQCT scan (based on their pharmacy data) were also included.

The present study includes cross-sectional data from participants with T2DM who completed the baseline survey between November 2010 and September 2013 and returned to the research center between March 2015 and February 2016 for the HR-pQCT scan of the distal radius. Dispensing records were collected at the pharmacy for all participants who gave written informed consent for the collection of their drug dispensing history. Dispensing data was available from January 1st 1991 through the date of the HR-pQCT scan and contained the product name, the anatomical therapeutical chemical (ATC) code [18], the dispensed quantity, the dispensing date and the prescribed daily dose [19]. When a participant had a prescription for insulin (ATC code A10A) in the six months before the date of the HR-pQCT scan, the participant was classified as current insulin user. All other T2DM participants were classified as non-insulin users. The mean time since first prescription of insulin was calculated from the prescription data.

The study has been approved by the institutional medical ethical committee (NL31329.068.10) and the Minister of Health, Welfare and Sports of the Netherlands (Permit 131,088-105,234-PG). All participants gave written informed consent.

\subsection{HR-pQCT imaging}

The non-dominant radius was scanned on an HR-pQCT scanner (Xtreme-CT; Scanco Medical AG, Brüttisellen, Switzerland) using the standard in vivo protocol as described in literature $[20,21]$. If the patient has previously sustained a distal radius fracture at the non-dominant site, the dominant site was scanned. The forearm was placed into a carbon fiber cast. An anteroposterior scout projection of the scan site was acquired for positioning of the tomographic acquisition. A reference line was placed on the radial joint surface. The scan volume spanned $9.02 \mathrm{~mm}$ in length and started $9.5 \mathrm{~mm}$ from the reference line in the proximal direction. Images were reconstructed using an isotropic voxelsize of $82 \mu \mathrm{m}$, resulting in 110 consecutive slices. Total scan time was $2.8 \mathrm{~min}$, with each acquisition resulting in an effective dose of approximately $3 \mu \mathrm{Sv}$. All scans were graded with regard to motion, and scans with quality 4 or 5 were repeated once [22]. Only scans with quality 1 to 3 were used for subsequent image analysis [23].

\subsection{Image analysis of $H R-p Q C T$ scans}

All scans were evaluated using the standard patient evaluation protocol that was provided by the manufacturer and that has been described previously in detail [24-26]. First, the periosteal contour was automatically derived and manually modified when contours visually deviated from the periosteal boundary [27]. The images were 
automatically segmented and the following bone density parameters were calculated from the images: total vBMD, trabecular vBMD and cortical vBMD. In the trabecular region, the micro-architectural parameters trabecular number, trabecular thickness and trabecular separation were calculated. For the cortical region, cortical thickness was calculated. In addition, extended analysis of the cortical compartment was performed to obtain cortical pore volume, cortical porosity and mean cortical pore diameter [28]. Cortical pore volume was calculated as the volume of all voxels identified as intracortical pore space. Cortical porosity was calculated as the ratio of the cortical pore volume to the total volume of the cortical compartment.

Micro-finite element analysis was performed by creating micro-finite element models directly from the segmented HR-pQCT images as described previously $[29,30]$. In short, all voxels representing bone tissue were converted into brick elements of the same size. A Young modulus of $10 \mathrm{GPa}$ and a Possion ratio of 0.3 were assigned to every element. Compression stiffness and estimated failure load were determined by applying a virtual "high-friction' compression test in the axial direction [29].

\subsection{Covariates}

All covariates were determined at the baseline visit between November 2010 and September 2013. Weight and height were measured without shoes and wearing light clothing using a scale and stadiometer to the nearest $0.5 \mathrm{~kg}$ or $0.1 \mathrm{~cm}$ (Seca, Hamburg, Germany). BMI was calculated by dividing weight in kilogram by height in meters squared. HbA1c level and creatinine level were determined as described elsewhere [16]. Alcohol use, smoking status (never, former or current), a history of a fracture at or above the age of 50 and T2DM duration were recorded at the baseline visit [18]. Alcohol consumption was classified into three categories: non-consumers, low consumers ( $\leq 7$ glasses per week for women and $\leq 14$ glasses per week for men), and high consumers ( $>7$ glasses per week for women and $>14$ glasses per week for men).

For the current study, the time between the baseline visit and the date of the HR-pQCT scan was added to the T2DM duration at baseline. If T2DM duration was not available, it was estimated by the time between the first antihyperglycemic prescription and the date of the HRpQCT scan. Use of other antihyperglycemic drugs in the six months before the date of the HR-pQCT scan was determined by the prescription data using ATC codes: metformin (ATC code A10BA02, A10BD02,03,05,07,08,10,11,13-18), sulfonylurea derivate (ATC code A10BB, A10BD01, A10BD02), dipeptidyl peptidase 4 inhibitor (ATC code $A 10 B H)$, thiazolidinedione (A10BG) or other blood glucose lowering drugs (A10BX). Use of anti-osteoporotic drugs and use of systemic corticosteroids in the six months before the date of the HR-pQCT scan was determined by the prescription data using ATC codes: drugs affecting bone structure and mineralization (M05B) and corticosteroids for systemic use (H02).

\subsection{Statistical analysis}

General characteristics were compared between the insulin and non-insulin users. The independent student's $t$-test or the Mann-Whitney $U$ test was used to test for significant differences of continuous normal or not-normal distributed variables and a chi-square test for differences in categorical variables. Log-transformation was performed if variables showed a skewed distribution. Multiple linear regression analysis was used to estimate the association between current use of insulin and HR-pQCT derived parameters as compared to the non-insulin users, yielding standardized beta's ( $\beta$ ) and 95\% confidence intervals (CIs). The same models were used for all regression analyses: model 1 was adjusted for age and sex, model 2 was additionally adjusted for BMI, HbA1c and duration of diabetes. A p-value $<0.05$ was considered statistically significant and analyses were conducted using SAS 9.4 (SAS Institute Inc., Cary, NC, USA).

\section{Results}

In total, data from 59 T2DM participants who had a HR-pQCT scan and pharmacy dispensing data available was retrieved. Data of eight participants were excluded due to extreme motion artifacts of the HRpQCT scan (grade $5 n=2$, grade $4 n=6$ ) and data from one participant was excluded because of extreme outliers. From the 50 included participants, 13 were classified as insulin user and 37 were classified as noninsulin user.

The general characteristics and the mean HR-pQCT derived bone parameters of the non-insulin and insulin users are shown in Table 1. The non-insulin users were slightly older, had a shorter time since first hyperglycemic prescription, a shorter duration of diabetes and lower mean HbA1c levels. There was no significant difference in the number of fractures at or above the age of 50 and the use of anti-osteoporotic drugs between the groups. Volumetric bone mineral density was lower in the insulin users when compared to the non-insulin users (total vBMD $-67.6 \mathrm{mgHA} / \mathrm{cm}^{3}, \mathrm{p}<0.01$; trabecular vBMD $-30.3 \mathrm{mgHA} / \mathrm{cm}^{3}, \mathrm{p}=0.03$; cortical vBMD $-54.16 \mathrm{mgHA} / \mathrm{cm}^{3}, \mathrm{p}=$ 0.06 ). Except for trabecular thickness being significantly lower in the insulin users $(-0.01 \mathrm{~mm}, \mathrm{p}<0.01)$, there were no differences in the trabecular micro-architecture between the groups. The cortical microarchitecture of the insulin users was unfavorable compared to the non-insulin users (cortical thickness $-0.20 \mathrm{~mm}, \mathrm{p}=0.02$; cortical pore volume $-5.80 \mathrm{~mm}^{3}, \mathrm{p}=0.03$; cortical porosity $-2.38 \%, \mathrm{p}=$ 0.38 ; cortical pore diameter $-0.01 \mathrm{~mm}, \mathrm{p}=0.08$ ). Bone strength was also lower in the insulin users (bone stiffness $-18.39 \mathrm{kN} / \mathrm{mm}, \mathrm{p}=$ 0.04 ; failure load $-815.41 \mathrm{~N}, \mathrm{p}=0.05$ ) when compared to the non-insulin users.

The association between insulin use and HR-pQCT derived bone parameters is shown in Table 2. After adjustment for age, sex, BMI, HbA1c and diabetes duration (model 2), current insulin use was associated with parameters of volumetric bone mineral density, bone micro-architecture and bone strength (volumetric bone mineral density: lower total vBMD $(\beta-0.56(95 \% \mathrm{CI}-0.89--0.24))$, trabecular vBMD $(\beta$ $-0.58(95 \% \mathrm{CI}-0.87--0.30))$; micro-architecture: trabecular thickness $(\beta-0.55(95 \% \mathrm{CI}-0.87--0.23))$, cortical thickness $(\beta-0.41$ (95\% CI $-0.74--0.08)$ ), cortical pore volume $(\beta-0.43$ (95\% CI $-0.73--0.13))$; strength: bone stiffness $(\beta-0.39(95 \% \mathrm{CI}-0.62-$ $-0.17)$ ), failure load $(\beta-0.39(95 \% \mathrm{CI}-0.60--0.17))$ as compared to the non-insulin users. Current insulin use was not associated with cortical vBMD, trabecular number, trabecular separation, cortical porosity and cortical pore diameter.

\section{Discussion}

The present study examined the association between current insulin use and HR-pQCT derived bone parameters in patients with T2DM. Literature on the association between insulin therapy and BMD in T2DM patients is scarce and there are no studies available that examined the effects of insulin therapy on bone micro-architecture or bone strength. Only two small studies have examined the association between insulin dose and BMD, and both found a positive association [12,13]. In contrast to these studies as well as our own hypothesis, the present study shows that current insulin use was associated with lower total vBMD, trabecular vBMD, trabecular thickness, cortical thickness, cortical pore volume, bone stiffness and failure load as compared to non-insulin users after adjustment for potential confounders.

In previous studies it was reported that insulin use is associated with an increased fracture risk in T2DM patients [7]. The mechanisms leading to this increased fracture risk are not completely understood, but a direct negative effect of insulin use of bone was thought to be unlikely because in-vitro studies showed that insulin is an anabolic bone agent [8]. 
Table 1

General characteristics of the study population.

\begin{tabular}{|c|c|c|c|}
\hline & $\begin{array}{l}\text { Non-insulin users } \\
(\mathrm{n}=37)\end{array}$ & $\begin{array}{l}\text { Insulin users } \\
(\mathrm{n}=13)\end{array}$ & p-value \\
\hline Age, years & $62.9(7.6)$ & $60.4(5.9)$ & 0.50 \\
\hline Female & $15(40.5)$ & $6(46.2)$ & 0.72 \\
\hline BMI, $\mathrm{kg} / \mathrm{m}^{2}$ & $30.3(5.0)$ & $30.9(5.4)$ & 0.71 \\
\hline \multicolumn{4}{|l|}{ Smoking status } \\
\hline Current & $6(16.2)$ & $0(0)$ & \multirow{4}{*}{0.08} \\
\hline Former & $17(45.9)$ & $10(76.9)$ & \\
\hline Never & $13(35.1)$ & $2(15.4)$ & \\
\hline Missing & $1(2.7)$ & $1(7.7)$ & \\
\hline \multicolumn{4}{|l|}{ Alcohol use } \\
\hline None & $6(16.2)$ & $5(38.4)$ & \multirow{4}{*}{0.19} \\
\hline Low & $20(54.1)$ & $4(30.8)$ & \\
\hline High & $10(27.0)$ & $3(23.1)$ & \\
\hline Missing & $1(2.7)$ & $1(7.7)$ & \\
\hline $\begin{array}{l}\text { Time since first antihyperglycemic } \\
\text { prescription, years }\end{array}$ & $4.1[5.0]$ & $8.5[8.3]$ & $<\mathbf{0 . 0 1}$ \\
\hline $\begin{array}{l}\text { Time since first insulin } \\
\text { prescription, years }\end{array}$ & $\mathrm{n} / \mathrm{a}$ & $7.0[4.7]$ & $\mathrm{n} / \mathrm{a}$ \\
\hline \multicolumn{4}{|l|}{$\begin{array}{l}\text { Use of drugs six months prior to the } \\
\text { scan }\end{array}$} \\
\hline Metformin & $26(70.3)$ & $8(61.5)$ & 0.56 \\
\hline Sulfonylurea derivatives & $6(16.2)$ & $0(0)$ & 0.12 \\
\hline Dipeptidyl peptidase 4 inhibitors & $0(0)$ & $2(15.4)$ & $<\mathbf{0 . 0 1}$ \\
\hline Thiazolidinediones & $0(0)$ & $0(0)$ & $\mathrm{n} / \mathrm{a}$ \\
\hline Other antihyperglycemic drugs & $0(0)$ & $0(0)$ & $\mathrm{n} / \mathrm{a}$ \\
\hline Systemic corticosteroids & $2(5.4)$ & $1(7.7)$ & 0.77 \\
\hline Anti-osteoporotic drugs & $1(2.7)$ & $1(7.7)$ & 0.43 \\
\hline $\begin{array}{l}\text { History of a fracture } \geq 50 \text { years of } \\
\text { age }\end{array}$ & $5(13.5)$ & $0(0)$ & 0.16 \\
\hline Duration of diabetes, years & $4.1[3.2]$ & $14.7[6.0]$ & $<\mathbf{0 . 0 1}$ \\
\hline $\mathrm{HbA1c}, \%$ & $6.6(0.7)$ & $7.7(0.8)$ & $<\mathbf{0 . 0 1}$ \\
\hline Creatinine, $\mu \mathrm{mol} / \mathrm{L}$ & $77.5(19.6)$ & $79.9(17.4)$ & 0.70 \\
\hline \multicolumn{4}{|l|}{ Quality grade of HR-pQCT scan } \\
\hline 1 & $8(21.1)$ & $3(23.1)$ & \multirow{3}{*}{0.87} \\
\hline 2 & $21(55.3)$ & $6(46.2)$ & \\
\hline 3 & $9(23.7)$ & $4(30.8)$ & \\
\hline \multicolumn{4}{|c|}{ HR-pQCT derived bone parameters } \\
\hline Total vBMD, mgHA/ $\mathrm{cm}^{3}$ & $326.2(75.6)$ & $258.6(61.0)$ & $<\mathbf{0 . 0 1}$ \\
\hline Trabecular vBMD, $\mathrm{mgHA} / \mathrm{cm}^{3}$ & $173.1(44.2)$ & $142.9(32.8)$ & 0.03 \\
\hline Cortical vBMD, $\mathrm{mgHA} / \mathrm{cm}^{3}$ & $854.0(82.9)$ & 799.9 (95.5) & 0.06 \\
\hline \multicolumn{4}{|l|}{ Bone micro-architecture } \\
\hline Trabecular number, $\mathrm{mm}^{-1}$ & $1.95(0.37)$ & $1.95(0.35)$ & 0.98 \\
\hline Trabecular thickness, mm & $0.07(0.01)$ & $0.06(0.01)$ & $<\mathbf{0 . 0 1}$ \\
\hline Trabecular separation, $\mathrm{mm}$ & $0.47(0.17)$ & $0.47(0.10)$ & 0.99 \\
\hline Cortical thickness, mm & $0.84(0.26)$ & $0.64(0.24)$ & 0.02 \\
\hline Cortical pore volume, $\mathrm{mm}^{3}$ & $19.10(8.76)$ & $13.30(5.79)$ & 0.03 \\
\hline Cortical porosity, $\%$ & $3.36(1.21)$ & $2.98(1.64)$ & 0.38 \\
\hline $\begin{array}{l}\text { Cortical pore diameter, } \mathrm{mm} \\
\text { Bone strength }\end{array}$ & $0.18(0.02)$ & $0.17(0.02)$ & 0.08 \\
\hline Bone stiffness, $\mathrm{kN} / \mathrm{mm}$ & $100.5(27.7)$ & $82.1(23.3)$ & 0.04 \\
\hline Failure load, $\mathrm{N}$ & $4796.5(1298.2)$ & $\begin{array}{l}3981.1 \\
(1101.5)\end{array}$ & 0.05 \\
\hline
\end{tabular}

Continues variables are presented as mean (SD) or median [IQR], categorical variables as number of participants (\%). P-values in bold are statistically significant. Abbreviations: HbA1c, glycated hemoglobin A1c; HR-pQCT, high resolution peripheral quantitative computed tomography; n/a, not applicable; vBMD, volumetric bone mineral density.

It was proposed that insulin use may be a surrogate for disease severity and disease duration as insulin is most often used by T2DM patients with long disease duration. The observed increased fracture risk in insulin users may therefore be due to factors associated with the disease itself. For example, complications of T2DM and risk factors for falling such as diabetic neuropathy and retinopathy are more common in patients with long disease duration, and one of the proposed mechanisms of the increased fracture risk in insulin users was therefore an increased falling frequency. Additionally, it may be hypothesized that insulin users are generally more insulin resistant than non-insulin users. Insulin resistance may result in impaired insulin signaling in osteoblasts, which leads to impaired bone micro-architecture due to deteriorated osteoblast proliferation, differentiation and survival [31]. Insulin resistance may therefore be another mechanism leading to the observed increased
Table 2

The association between insulin use and HR-pQCT derived bone parameters.

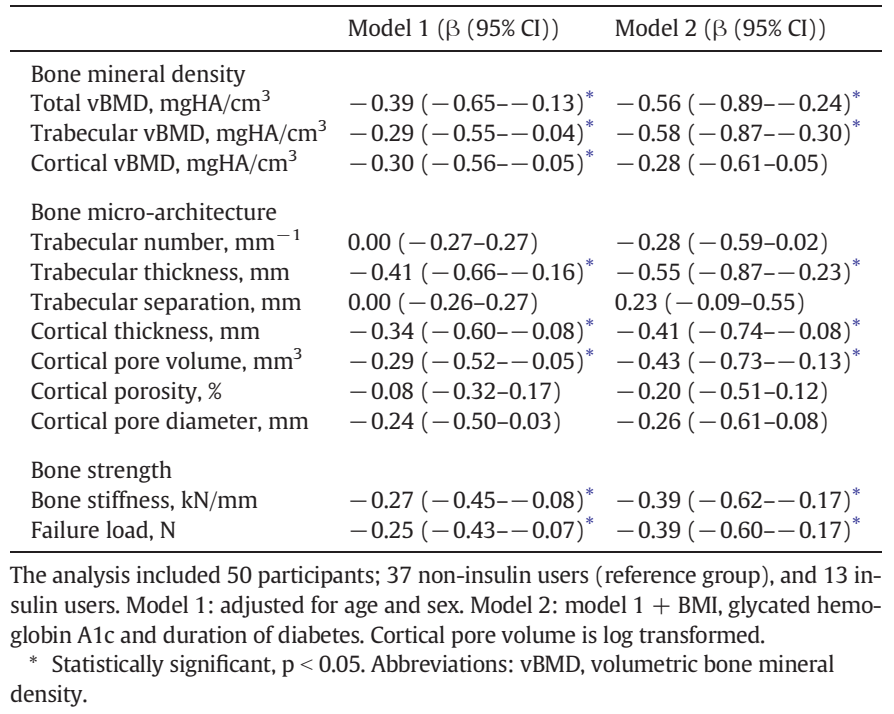

fracture risk in insulin users. Alternatively, a study in patients with T2DM showed beta-cell decay over time [32], which leads to a decrease in the endogenous insulin production and contributes negatively to bone quality. In our study, the diabetes duration of the insulin users was longer than the non-insulin users (14.7 vs 4.1 year, respectively), and hypoinsulinemia may thus be more prominently present in the insulin users, while substitution with exogenous insulin may not completely mimic the effects of endogenous insulin. Furthermore, the cumulative effect of chronic hyperglycemia will be larger in insulin users than in non-insulin users. Long-term hyperglycemia may have several negative effects on bone architecture, such as an increased formation and accumulation of AGE's, which result in impaired bone collagen quality and thereby decreased bone strength [33]. Elevated blood glucose levels also lead to hypercalcuria [34], which may influence bone mineralization. Finally, insulin users may be sarcopenic more often than non-insulin users [35]. As muscle strength influences bone strength, this may be another mechanism resulting in an increased fracture risk.

Although the results in this study are adjusted for HbA1c and disease duration, which were used as proxies for effect of the disease itself, there may still be residual confounding by other factors related to disease severity. Further information regarding disease severity such as the presence of micro- and macrovascular complications will be very useful to take into account, but for this study we did not have this information. Additionally, we had no HR-pQCT data of participants with an impaired fasting glucose (IFG) or impaired glucose tolerance (IGT). Inclusion of a group with IFG or IGT could help to test some of the above mentioned hypotheses about the mechanism whereby insulin use is negatively associated with HR-pQCT derived bone parameters.

Previous studies showed that T2DM is a low bone turnover condition, as both markers of bone formation and bone resorption are lower in patients with T2DM than in healthy subjects [36,37]. It may be hypothesized that changes in bone micro-architecture may be mediated by changes in bone turnover markers, i.e. unfavorable vBMD, bone micro-architecture and bone strength such as observed in our study are accompanied by or preceded by an increase in bone resorption markers while the bone formation markers are stable or decreased. Although no literature is available on the effect of exogenous insulin substitution on bone turnover markers, a study by Basu et al. found no alterations in bone turnover markers during physiological changes in insulin levels [38]. Additionally, higher levels of serum insulin were associated with increased levels of the bone turnover markers [39], decreased levels of bone resportion markers, and increased vBMD of the subtrochanteric 
femur on low-resolution CT [40]. Unfortunately, no data on bone turnover markers was available in our study either. Future studies examining the association between insulin use and HR-pQCT derived bone parameters should also measure bone turnover markers to verify this hypothesis. Furthermore, DXA scans of the participants were not available. Due to the small number of participants we were not able to adjust for potential confounders such as use of glucocorticoids, a history of a fracture at or above the age of 50, a parental history of hip fracture, vascular complications of diabetes and menopausal status. Within the noninsulin user group there were some users of glucocorticoids, and use of them has been associated with increased fracture risk [42] and this might have confounded the investigated association. Finally, we used an automatic instead of a semi-automatic algorithm to calculate cortical bone parameters. It has been argued that on top of a trabecular and cortical region, a transitional zone (the region between the trabecular and cortical region) should be identified $[43,44]$. In this manuscript, the endocortical contour was not manually adjusted to prevent intra-operator variability, and this may have resulted in over- or underestimation of the cortical bone parameters.

This study has some limitations. First, this study has a cross-sectional design and because of this design we can only speculate about the mechanisms whereby insulin use is associated with impaired bone quality. Second, because special clearance for radiological examinations within The Maastricht Study by the Dutch Ministry of Health was required, HR-pQCT measurements started later during the course of the study. Therefore, HR-pQCT data were available for a relatively small number of participants resulting in reduced power of the study which may have led to over- or underestimation of the associations [41]. The present results should therefore be interpreted with caution. HR-pQCT scans of the distal tibia were only recently allowed within the Maastricht Study and therefore these scans were not available in our study population. Since the distal tibia is a weight bearing bone, in contrast to the distal radius, the association between insulin use and HR-pQCT derived bone parameters at the distal tibia may be different and is subject for future analyses. Additionally, no information on vitamin $D$ and parathyroid hormone levels were available for the study population and therefore patients with secondary osteoporosis may have been included.

In conclusion, in this cross-sectional study we found that insulin use was negatively associated with bone mineral density, bone micro-architectural and bone strength parameters at the distal radius measured with HR-pQCT in T2DM patients. Therefore, the previously observed increased fracture risk in insulin users might be partly due to bone fragility, although there may be residual confounding by other factors related to disease severity in insulin users. Replication of these findings in larger, preferably longitudinal studies is needed.

\section{Authors' roles}

Study design: EdW, JD, FdV and JvdB. Data collection: EdW, JD, RH, MS, PD, CvdK, SS, CS, NS, AK. Data analysis: EdW and JD. Data interpretation: EdW, AD, JdJ, FdV, JvdB. Drafting manuscript: EdW, AD, FdV, JvdB. Revising manuscript content: All authors. Approving final version of manuscript: All authors. EdW and AD take responsibility for the integrity of the data analysis.

\section{Funding}

This study was supported by the European Regional Development Fund via OP-Zuid, the Province of Limburg, the Dutch Ministry of Economic Affairs (grant 310.041), Stichting De Weijerhorst (Maastricht, the Netherlands), the Pearl String Initiative Diabetes (Amsterdam, the Netherlands), the Cardiovascular Center (CVC, Maastricht, the Netherlands), Cardiovascular Research Institute Maastricht (CARIM, Maastricht, the Netherlands), School for Public Health and Primary Care (CAPHRI, Maastricht, the Netherlands), School for Nutrition, Toxicology and Metabolism (NUTRIM, Maastricht, the Netherlands), Stichting Annadal (Maastricht, the Netherlands), Health Foundation Limburg (Maastricht, the Netherlands) and by unrestricted grants from Janssen-Cilag B.V. (Tilburg, the Netherlands), Novo Nordisk Farma B.V. (Alphen aan den Rijn, the Netherlands) and Sanofi-Aventis Netherlands B.V. (Gouda, the Netherlands).

\section{Declaration of interest}

\section{Conflicts of interest}

None.

\section{Acknowledgements}

We thank all participants of the Maastricht Study, their community pharmacists and the Apothekers Vereniging Maastricht for their cooperation.

\section{References}

[1] G. Danaei, M.M. Finucane, Y. Lu, G.M. Singh, M.J. Cowan, C.J. Paciorek, et al., National, regional, and global trends in fasting plasma glucose and diabetes prevalence since 1980: systematic analysis of health examination surveys and epidemiological studies with 370 country-years and 2.7 million participants, Lancet 378 (9785) (2011) 31-40.

[2] A.V. Schwartz, D.E. Sellmeyer, K.E. Ensrud, J.A. Cauley, H.K. Tabor, P.J. Schreiner, S.A. Jamal, D.M. Black, Cummings SR; study of osteoporotic features research group. Older women with diabetes have an increased risk of fracture: a prospective study, J. Clin. Endocrinol. Metab. 86 (1) (2001) 32-38.

[3] P. Vestergaard, Discrepancies in bone mineral density and fracture risk in patients with type 1 and type 2 diabetes-a meta-analysis, Osteoporos. Int. 18 (4) (2007) 427-444.

[4] E.A. de Waard, T.A. van Geel, H.H. Savelberg, A. Koster, P.P. Geusens, J.P. van den Bergh, Increased fracture risk in patients with type 2 diabetes mellitus: an overview of the underlying mechanisms and the usefulness of imaging modalities and fracture risk assessment tools, Maturitas 79 (3) (2014) 265-274.

[5] N. Napoli, M. Chandran, D.D. Pierroz, B. Abrahamsen, A.V. Schwartz, S.L. Ferrari, Mechanisms of diabetes mellitus-induced bone fragility, Nat. Rev. Endocrinol. 13 (4) (2017) 208-219.

[6] A. Palermo, L. D'Onofrio, R. Eastell, A.V. Schwartz, P. Pozzili, N. Napoli, Oral antidiabetic drugs and fracture risk, cut to the bone: safe or dangerous? A narrative review, Osteoporos. Int. 26 (8) (2015) 2073-2089.

[7] M.P. Gilbert, E. Pratley, The impact of diabetes and diabetes medications on bone health, Endocr. Rev. 36 (2) (2015) 194-213.

[8] K.M. Thrailkill, C.K. Lumpkin Jr., R.C. Bunn, S.F. Kemp, J.L. Fowlkes, Is insulin an anabolic agent in bone? Dissecting the diabetic bone for clues, Am. J. Physiol Endocrinol. Metab. 289 (5) (2005) E735-E745.

[9] R.P. Stolk, P.L. van Daele, H.A. Pols, H. Burger, A. Hofman, J.C. Birkenhäger, S.W Lamberts, D.E. Grobbee, Hyperinsulinemia and bone mineral density in an elderly population: the Rotterdam Study, Bone 18 (6) (1996) 545-549.

[10] E. Barret-Conner, D. Kritz-Silverstein, Does hyperinsulinemia preserve bone? Diabetes Care 19 (1996) 1388-1392.

[11] I.R. Reid, M.C. Evans, G.J.S. Cooper, R.W. Ames, J. Stapleton, Circulating insulin levels are related to bone density in postmenopausal women, Am. J. Physiol. Endocrinol. Metab. 265 (1993) E655-E659.

[12] Y. Fukunaga, J. Minamikawa, D. Inoue, H. Koshiyama, Does insulin use increase bone mineral density in patients with non-insulin-dependent diabetes mellitus? Arch. Intern. Med. 157 (1997) 2668-2669.

[13] R.S. Weinstock, R.S. Goland, E. Shane, T.L. Clemens, R. Lindsay, J.P. Bilezikian, Bone mineral density in women with type II diabetes mellitus, J. Bone Miner. Res. 4 (1989) 97-101.

[14] P. Geusens, R. Chapurlat, G. Schett, A. Ghasem-Zadeh, E. Seeman, J. de Jong, J. van den Bergh, High-resolution in vivo imaging of bone and joints: a window to microarchitecture, Nat. Rev. Rheumatol. 10 (5) (2014) 304-313.

[15] J.A. MacNeil, S.K. Boyd, Accuracy of high-resolution periph-eral quantitative computed tomography for measurement of bone quality, Med. Eng. Phys. 29 (10) (2007) 1096-1105.

[16] M.T. Schram, S.J.S. Sep, C.J. van der Kallen, P.C. Dagnelie, A. Koster, N. Schaper, R.M.A Henry, C.D.A. Stehouwer, The Maastricht Study: an extensive phenotyping study on determinants of type 2 diabetes, its complications and its comorbidities, Eur. J. Epidemiol. 29 (6) (2014) 439-451.

[17] World Health Organization, Definition and diagnosis of diabetes mellitus and intermediate hyperglycemia: report of a WHO/IDF consultation, 2006 (Geneva, Switzerland).

[18] WHO's ATC/DDD index 2016 [internet]. Oslo: WHO Collaborating Centre for Drug Statistics Methodology ([updated 2015 Dec 16; cited 2016 Nov 3]. Available from:) http://www.whocc.no/atc_ddd__index/. 
[19] J.T. Nielen, J.H. Driessen, P.C. Dagnelie, A. Boonen, B. van den Bemt, H.A. van Onzenoort, et al., Drug utilisation in the Maastricht Study: a comparison with nationwide data, Forthcoming, 2016.

[20] S. Boutroy, M.L. Bouxsein, F. Munoz, P.D. Delmas, In vivo assessment of trabecular bone microarchitecture by high-resolution peripheral quantitative computed tomography, J. Clin. Endocrinol. Metab. 90 (12) (2005) 6508-6515.

[21] S. Khosla, B.L. Riggs, E.J. Atkinson, A.L. Oberg, L.J. McDaniel, M. Holets, et al., Effects of sex and age on bone microstructure at the ultradistal radius: a population-based noninvasive in vivo assessment, J. Bone Miner. Res. 21 (1) (2006) 124-131.

[22] J.B. Pialat, A.J. Burghardt, M. Sode, T.M. Link, S. Majumdar, Visual grading of motion induced image degradation in high resolution peripheral computed tomography: impact of image quality on measures of bone density and micro-architecture, Bone 50 (1) (2012) 111-118.

[23] Y. Pauchard, A.M. Liphardt, H.M. Macdonald, D.A. Hanley, S.K. Boyd, Quality control for bone quality parameters affected by subject motion in high-resolution peripheral quantitative computed tomography, Bone 50 (6) (2012) 1304-1310.

[24] A. Laib, H.J. Hauselmann, P. Rüegsegger, In vivo high resolution 3D-QCT of the human forearm, Technol. Health Care 6 (5-6) (1998) 329-337.

[25] A. Laib, P. Rüegsegger, Comparison of structure extraction methods for in vivo trabecular bone measurements, Comput. Med. Imaging Graph. 23 (2) (1999) 69-74.

[26] T. Hildebrand, P. Rüegsegger, A new method for the model-independent assessment of thickness in three-dimensional images, J. Microsc. 185 (1) (1997) 67-75.

[27] H.R. Buie, G.M. Campbell, R.J. Klinck, J.A. MacNeil, S.K. Boyd, Automatic segmentation of cortical and trabecular compartments based on a dual threshold technique for in vivo micro-CT bone analysis, Bone 41 (4) (2007) 505-515.

[28] A.J. Burghardt, H.R. Buie, A. Laib, S. Majumdar, S.K. Boyd, Reproducibility of direct quantitative measures of cortical bone microarchitecture of the distal radius and tibia by HR-pQCT, Bone 47 (3) (2010) 519-528.

[29] W. Pistoia, B. van Rietbergen, E.M. Lochmüller, C. A. Lill, F. Eckstein, P. Rüegsegger, Estimation of distal radius failure load with micro-finite element analysis models based on three-dimensional peripheral quantitative computed tomography images, Bone 30 (6) (2002) 842-848.

[30] N. Dalzell, S. Kaptoge, N. Morris, A. Berthier, B. Koller, L. Braak, B. van Rietbergen, ]. Reeve, Bone micro-architecture and determinants of strength in the radius and tibia: age-related changes in a population-based study of normal adults measured with high-resolution pQCT, Osteoporos. Int. 20 (10) (2009) 1683-1694.

[31] S.N. Pramojanee, M. Phimphilai, N. Chattipakorn, S.C. Chattipakorn, Possible role of insulin signaling in osteoblasts, Endocr. Res. 39 (4) (2014) 144-151.

[32] U.K. Prospective Diabetes Study Group, U.K. prospective diabetes study 16 . Overview of 6 years' therapy of type II diabetes: a progressive disease, Diabetes 44 (11) (1995) 1249-58
[33] S.Y. Goh, M.E. Cooper, Clinical review: The role of advanced glycation end products in progression and complications of diabetes, J. Clin. Endocrinol. Metab. 93 (4) (2008) 1143-1152.

[34] F. Gregorio, S. Cristallini, F. Santeusanio, P. Filipponi, P. Fumelli, Osteopenia associated with non-insulin-dependent diabetes mellitus: what are the causes? Diabetes Res. Clin. Pract. 23 (1) (1994) 43-54.

[35] T.J. Beck, T.L. Oreskovic, K.L. Stone, C.B. Ruff, K. Ensrud, M.C. Nevitt, et al., Structural adaptation to changing skeletal load in the progression toward hip fragility: the study of osteoporotic fractures, J. Bone Miner. Res. 16 (6) (2001) 1108-1119.

[36] J. Starup-Linde, S.A. Eriksen, S. Lykkeboe, A. Handberg, P. Vestergaard, Biochemical markers of bone turnover in diabetes patients - a meta-analysis, and a methodological study on the effects of glucose on bone markers, Osteoporos. Int. 25 (6) (2014) 1697-1708.

[37] K. Hygum, J. Starup-Linde, T. Harsløf, P. Vestergaard, B.L. Langdahl, Mechanisms in endocrinology: Diabetes mellitus, a state of low bone turnover - a systematic review and meta-analysis, Eur. J. Endocrinol. 176 (3) (2017) R137-R157.

[38] R. Basu, J. Peterson, R. Rizza, S. Khosla, Effects of physiological variations in circulating insulin levels on bone turnover in humans, J. Clin. Endocrinol. Metab. 96 (5) (2011) 1450-1455.

[39] I. Levinger, E. Seeman, G. Jerums, G.K. McConell, M.S. Rybchyn, S. Cassar, et al., Glucose-loading reduces bone remodeling in women and osteoblast function in vitro, Phys. Rep. 4 (3) (2016).

[40] M. Osima, R. Kral, T.T. Borgen, I.K. Høgestøl, R.M. Joakimsen, E.F. Eriksen, A. Bjørnerem, Women with type 2 diabetes mellitus have lower cortical porosity of the proximal femoral shaft using low-resolution CT than nondiabetic women, and increasing glucose is associated with reduced cortical porosity, Bone 97 (2017) 252-260.

[41] K.S. Button, J.P. Ioannidis, C. Mokrysz, B.A. Nosek, J. Flint, E.S. Robinson, M.R. Munafò, Power failure: why small sample size undermines the reliability of neuroscience, Nat. Rev. Neurosci. 14 (5) (2013) 365-376.

[42] T.P. van Staa, H.G. Leufkens, L. Abenhaim, B. Zhang, C. Cooper, Use of oral corticosteroids and risk of fractures, J. Bone Miner. Res. 15 (2000) 993-1000.

[43] R. Zebaze, E. Seeman, Cortical bone: a challenging geography, J. Bone Miner. Res. 30 (1) (2015) 24-29.

[44] R. Zebaze, A. Ghasem-Zadeh, A. M'bala, E. Seeman, A new method of segmentation of compact-appearing, transitional and trabecular compartments and quantification of cortical porosity from high resolution peripheral quantitative computed tomographic images, Bone 54 (2013) 8-20. 